\title{
Microstructure Changes and Phase Growth Occurring at the Interface of the AI/Ti Explosively Welded and Annealed Joints
}

\author{
D.M. Fronczek, R. Chulist, L. Litynska-Dobrzynska, Z. Szulc, P. Zieba, and J. Wojewoda-Budka
}

\author{
(Submitted November 6, 2015; in revised form January 28, 2016; published online March 4, 2016)
}

\begin{abstract}
The manuscript presents a close examination of the titanium and aluminum platters manufactured by explosive welding method. In particular, the microstructure changes of the Al/Ti wavy shape interface after annealing at 773 and $903 \mathrm{~K}$ were studied. Three stable $\mathrm{TiAl}_{3}$, TiAl, and $\mathrm{Ti}_{3} \mathrm{Al}$ and a metastable $\mathrm{TiAl}_{2}$ intermetallic phases have been formed in the state directly after explosive welding. The orientation map and TEM images obtained after explosive welding process showed very fine grains of aluminum mixed with intermetallics in the interface region between the peninsulas or islands. After annealing for $100 \mathrm{~h} \mathrm{the} \mathrm{TiAl}_{3}$ continuous layer was obtained; however, the layer achieved at $903 \mathrm{~K}$ was much wider than that obtained at $773 \mathrm{~K}$. An examination of the growth kinetics at $903 \mathrm{~K}$ revealed that incubation time was less than 5 min. After this period, the growth was solely governed by chemical reaction.
\end{abstract}

Keywords aluminum, electron, heat treatment, intermetallic, joining, microscopy, titanium

\section{Introduction}

Difficulties associated with joining of dissimilar metals or alloys by conventional fusion joining methods are mostly related to difference in melting temperature, brittle phase formation, and internal stresses. This leads to a weak joint and makes the weld too brittle (Ref 1,2$)$. A way of overcoming this problem is to employ solid-state joining processes. One of the solid-state joining techniques for obtaining reliable joints between dissimilar materials is explosive welding method (EXW). In this process, the energy comes from the explosion of explosive materials, and the pressure of the flyer plate is propelled toward the base plate (Ref 3, 4). The main advantage of EXW is related to the ability of joining various shapes such as plate to plate (Ref 5) or tube to sleeve (Ref 4), and also it provides a high purity of the interface. The EXW technique is referred to the cold techniques, where the high temperature appears only locally (Ref 6). As a result of such a method, different

This article is an invited submission to JMEP selected from presentations at the Symposium "Joining Technologies," belonging to the Topic "Joining and Interfaces" at the European Congress and Exhibition on Advanced Materials and Processes (EUROMAT 2015), held September 20-24, 2015, in Warsaw, Poland, and has been expanded from the original presentation.

D.M. Fronczek, R. Chulist, L. Litynska-Dobrzynska, P. Zieba, and J. Wojewoda-Budka, Institute of Metallurgy and Materials Science Polish Academy of Sciences, 25 Reymonta Street, 30-059 Kraków, Poland; and Z. Szulc, Institute of Metallurgy and Materials Science Polish Academy of Sciences, 25 Reymonta Street, 30-059 Kraków, Poland; and High Energy Technologies Works 'Explomet', 100H Oswiecimska Street, 45-641 Opole, Poland. Contact e-mail: d.fronczek@imim.pl

intermetallic phases at the interface can be formed, for example, $\mathrm{TiAl}_{3}$ in titanium-aluminum (Ref 7 ), $\mathrm{FeAl}_{3}$ in aluminum-steel (Ref 8), and $\mathrm{CuAl}_{2}$ in copper-aluminum (Ref 9, 10).

Ti-Al phase diagram consists of three stable intermetallics $\left(\mathrm{Ti}_{3} \mathrm{Al}, \mathrm{TiAl}\right.$, and $\left.\mathrm{TiAl}_{3}\right)$ and one metastable $\left(\mathrm{TiAl}_{2}\right)$ phase $(\mathrm{Ref}$ 11). The $\mathrm{TiAl}_{3}$ phase is the most predicted one, because its formation is thermodynamically and kinetically favored. For instance, only this intermetallic phase $\left(\mathrm{TiAl}_{3}\right)$ formed at the interface after the diffusion bonding of $\mathrm{Ti}$ and $\mathrm{Al}$ plates in (Ref 12, 13). $\mathrm{TiAl}_{3}$ with Young's modulus equal to $216 \mathrm{GPa}$, higher oxidation resistance, and lower density $\left(3.3 \mathrm{~g} / \mathrm{cm}^{3}\right)$ is more expected than the other titanium aluminides (Ref 14). However, as solidification process during EXW goes far from the equilibrium conditions, the presence of another phases cannot be excluded (Ref 10).

Formation of the continuous layer of intermetallics is necessary in the metallic-intermetallic laminate (MIL) production. These materials are characterized by special mechanical properties due to their micro-, meso- and macrostructure. Therefore, they can be applied in aerospace or chemical industry (Ref 7, 15). Even if the continuous layer is not created in the state directly after explosion, which is often the case, further annealing allows to obtain a desired structure (Ref 7).

There are few reports concerning the EXW of Ti and Al. For example, ten plates of titanium and eleven plates of aluminum were explosively welded by Bataev et al. (Ref 6). In order to obtain a continuous intermetallic layer, the clads were annealed under the air atmosphere for various periods of time (from 1 to $100 \mathrm{~h})$ at $903 \mathrm{~K}$. MIL composites composed of $\mathrm{Ti} / \mathrm{TiAl}_{3} / \mathrm{Al}$ were analyzed in detail concerning their microstructure and mechanical properties. In Foadian et al.'s (Ref 16, 17) experiment, three titanium and three aluminum clads were successfully welded. The influence of temperature on the $\mathrm{TiAl}_{3}$ phase growth during annealing for various times [from 1 to $70 \mathrm{~h}$ (Ref 16) and 1 to $260 \mathrm{~h}(\operatorname{Ref} 17)]$ at $903 \mathrm{~K}$ under ambient atmosphere was examined too. In study of Pavliukova et al. (Ref 18), ten titanium sheets with nine aluminum sheets were joined using the EXW method and further annealed for $40 \mathrm{~h}$ at 
$913 \mathrm{~K}$ with or without external pressure of $12 \mathrm{MPa}$. Once again, the $\mathrm{TiAl}_{3}$ phase was the only one, which was present in the interconnection area. Despite the fact that the $\mathrm{Al} / \mathrm{Ti}$ explosively welded joints are commonly described in the literature, a detailed qualitative and quantitative analysis of their interfaces has not been performed so far. The presence of other than $\mathrm{TiAl}_{3}$ intermetallic phases was not taken into consideration as well.

Therefore, the main aim of the present study of the titaniumaluminum explosively welded samples was to investigate the microstructure and phase composition close to the interface as well as to compare the growth rate of the intermetallic phase under various temperatures $(903,825$, and $773 \mathrm{~K}$ ) and under vacuum atmosphere. This allows calculation of the kinetics of intermetallic growth and also answer the question what mechanisms govern the growth at given temperature of annealing.

\section{Experimental Procedure}

Aluminum (A1050) cold-rolled sheet with dimensions of $460 \mathrm{~mm}$ long, $140 \mathrm{~mm}$ wide, and $4 \mathrm{~mm}$ thick and titanium (Ti Gr. 2) cold-rolled sheet with dimensions of $460 \mathrm{~mm}$ long, $140 \mathrm{~mm}$ wide, and $0.8 \mathrm{~mm}$ thick were used as the base plate and flyer plate, respectively. They were separated by a stand-off distance equal to $1.5 \mathrm{~mm}$. An explosive material (ANFO) was placed on top of the flyer plate. The detonator was placed near the edge, in the middle of the plate width. The detonation velocity during explosion was 1900 to $1950 \mathrm{~m} / \mathrm{s}$, and the jetting direction was parallel to the rolling direction (RD).

Samples with dimensions of $12 \times 6 \times 4.8 \mathrm{~mm}^{3}$ were cut from the central part of the clad for further study. They were analyzed in the state directly after welding and after annealing at 903,825 , and $773 \mathrm{~K}$ for various times $(0.083,0.25,0.5,1$, $1.5,2,4,5,11,15,20,25,36,50,61,75,86$, and $100 \mathrm{~h})$. In annealing experiment samples were sealed in quartz ampoules. To obtain mirror-finished surfaces for microstructure and chemical composition analysis, all cross sections of the samples were polished using abrasive papers $(1000,3000$, and 5000) and diamond polishing pastes $(6$ and $0.25 \mu \mathrm{m})$ mixed with alumina.

Microstructural characterization of the region close to the Ti/ Al interface was done using optical microscope (OM) and scanning electron microscopes (SEM): PHILIPS XL30 equipped with LINK ISIS EDS system (Oxford Instrument) and FEI Quanta 3D FEG. The standard analyses were carried out at accelerating voltages of $12 \mathrm{kV}$ and working distance of $10.0 \mathrm{~mm}$. Furthermore, selected samples were analyzed using electron backscattered diffraction (EBSD) technique using FEI Quanta 3D FEG equipped with the TSL EBSD system. For EBSD, the surface was prepared using modified procedure (electrolyte Struers A3, voltage of $33 \mathrm{~V}$, electrolyte temperature of $283 \mathrm{~K}$, specimen temperature of $77 \mathrm{~K}$, polishing time $4 \times 5 \mathrm{~s}$ ) described in Ref 19. The following parameters were used in EBSD measurement: tilt angle $=70^{\circ}$, voltage $=20 \mathrm{kV}$, working distance $=10.0 \mathrm{~mm}$, and mappings step size $=0.27 \mu \mathrm{m}$. The samples were examined on longitudinal section (TD plane). Orientation determination of the individual grains was carried out using inverse pole figure (IPF) color codding indicating TD.

The thin foils for TEM observation were cut from the selected regions using a FEI Quanta 3D Dual Beam Focused Ion Beam (FIB) instrument. All thin foils contained titanium, interconnection area, and aluminum part. Further microstructure details were revealed using FEI TECNAI G2 FEG super TWIN $(200 \mathrm{kV})$ transmission electron microscope equipped with Phoenix EDS manufactured by EDAX.

In order to investigate the intermetallic layer thickness with a good statistics, a specialized computer program was used. The program examines 600 points over a particular area, providing the average width and standard deviation.

\section{Results and Discussion}

\subsection{Microstructure and Phase Constitution in the State Directly After EXW}

The cross section of the initial Ti/Al sample in the state directly after explosive welding is presented in Fig. 1. A joint of good quality was manufactured without any pores or cracks with a wavy type. Depending on the welding conditions, i.e., the collision angle, impact velocity, as well as the properties and geometry of the welded set-up, different interconnection shapes can be obtained (Ref 20). The larger the explosive load, the larger the wavelength and amplitude of wave obtained (Ref 20, 21). In our case, the average values of the amplitude was in the range from 10 to 20 $\mu \mathrm{m}$, while the wave period varied between 100 and $150 \mu \mathrm{m}$.

The obtained interface was not uniform but it had a complex structure: either flat or peninsula-like or island-like. The intermetallic phases were intensively swirled in peninsula- or islandlike structures, which was previously showed in Fig. 2 (Ref 22). The SEM/EDS analysis of these regions revealed stable titaniumaluminum phases $\mathrm{TiAl}_{3}, \mathrm{TiAl}$ and $\mathrm{Ti}_{3} \mathrm{Al}$. This result was previously confirmed by the synchrotron radiation experiment described in (Ref 22), where additionally the metastable $\mathrm{TiAl}_{2}$ phase was revealed. An example of peninsula- and island-like morphologies can also be found at the interfaces of explosively welded titanium and aluminum (Ref 7, 18, 23) or 2205 duplex stainless steel and X65 pipe steel (Ref 24). According to Zhang et al., conditions for manufacturing these structures are fulfilled when the detonation force is combined with intense metal vortex flow (Ref 24). However, the works of Xia et al. (Ref 23) and Zhang et al. (Ref 24) have not confirmed the presence of any intermetallic phase by means of SEM or TEM.

The EBSD technique allowed provide the complementary information to the classical microstructure observation in SEM. First of all, it allowed observe the microstructure changes in joined materials when approaching to their interface. The obtained EBSD maps were very similar to these obtained in the previous study (Ref 22).

In Fig. 2, the aluminum grains possessed typical cold-rolled microstructure with the grain size of 200-300 $\mu \mathrm{m}$ in length and $5-10 \mu \mathrm{m}$ in width. It is to note that in the $\mathrm{Ti} / \mathrm{Al}$ interface region, only some of fine aluminum grains were properly indexed. In the case of titanium clad, the deformation twins are present (Fig. 2). An increased amount of the twins near the joint is related to a higher deformation during EXW. However, many intermetallics grains are located randomly at the interface region along the whole interconnection. Figure 2 depicts that many of them were too small to be properly indexed; therefore, white region can be seen. This type of microstructure is representative for entire $\mathrm{Al} / \mathrm{Ti}$ interface obtained after explosion; however, there are few locations where the aluminum grains were big enough to be indexed properly [see Fig. 7a, b in (Ref 22)]. 

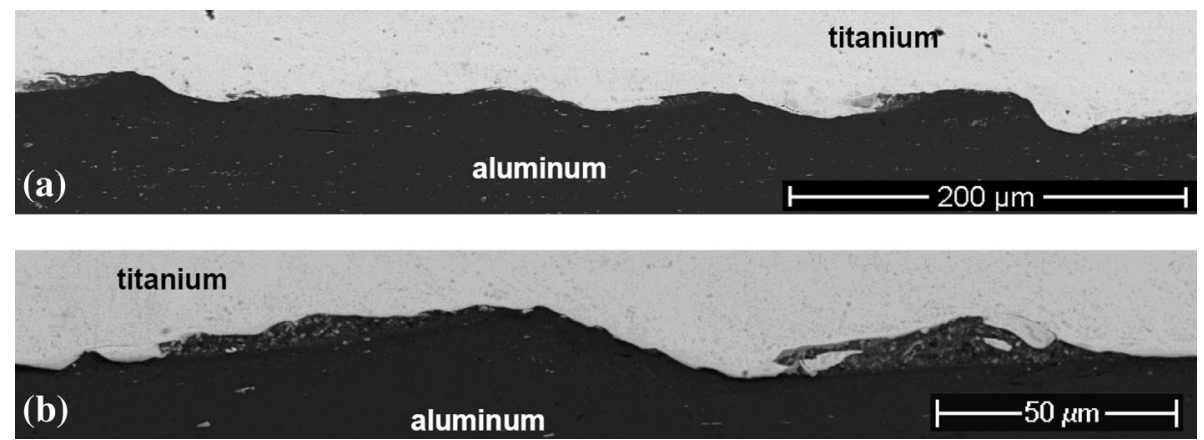

Fig. 1 (a-b) The SEM/BSE images of the initial sample

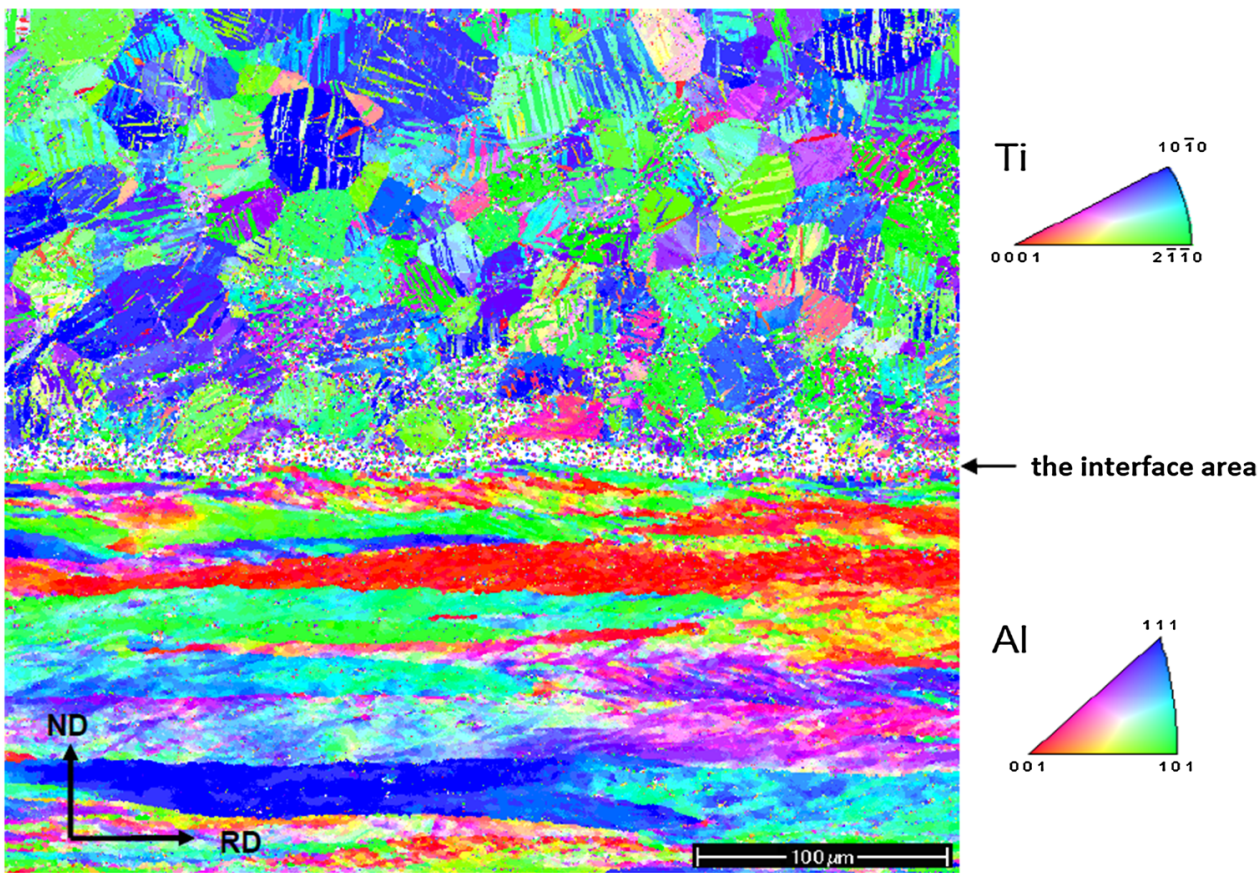

Fig. 2 SEM/EBSD IPF orientation map presenting the microstructures of Ti/Al in the state directly after explosion

The transmission electron microscopy (TEM) was involved as a next step to provide the microstructure and crystallographic description of the interface region. Due to high pressure during the joining process, the titanium grains located near interconnection region are remarkably deformed and fine (Fig. 2, 3a). As the temperature during joining process is not high enough, it does not initiate recrystallization in titanium phase. Aluminum grains located close to the interconnection are of polygonal shape (Fig. 3b). Since the recovery and recrystallization processes occurs much earlier in $\mathrm{Al}$ than in $\mathrm{Ti}$, the abnormal grain growth was observed in aluminum after EXW. Similar results were presented by Bataev et al. (Ref 7). In contrary to the following research and Ref (7), both micrograins and the abnormal grown grains were detected close to the interface in titanium clad, in work of Xia et al. (Ref 24). This shows that recrystallization of titanium can occur too.

The selected-area electron diffraction pattern (SADP) taken from the interface area revealed not only the presence of aluminum (reflections lying on the rings) but also some additional single weak reflections, which were circled in Fig. 3c. Therefore, in order to indicate them, the selected-area electron diffraction patterns taken from the individual grains were collected confirming the TiAl and $\mathrm{TiAl}_{2}$ phases (Fig. 3d, e). As it was mentioned before, during EXW the high values of temperature occur locally and for short period of time (Ref 6,25$)$. As a consequence, some regions can be melted locally (Ref 26) and cooled with a high cooling rates. This could be the reason why both stable and metastable phases can be obtained (Ref 13, 24). It is also important to mention that the welding process is running very rapidly; therefore, the melted materials may have the tendency to form amorphous phases. Their presence was not revealed in following paper, but it was detected in carbon or stainless steel/Zr, carbon steel/Ti, and stainless steel/Ta (Ref 25) explosively welded joints.

\subsection{Microstructure and Phase Analysis After Annealing}

Annealing experiment was carried out at three different temperatures: 903,825 , and $773 \mathrm{~K}$ for various time periods.

During annealing at $903 \mathrm{~K}$ under vacuum atmosphere, a continuous intermetallic layer between aluminum and titanium 


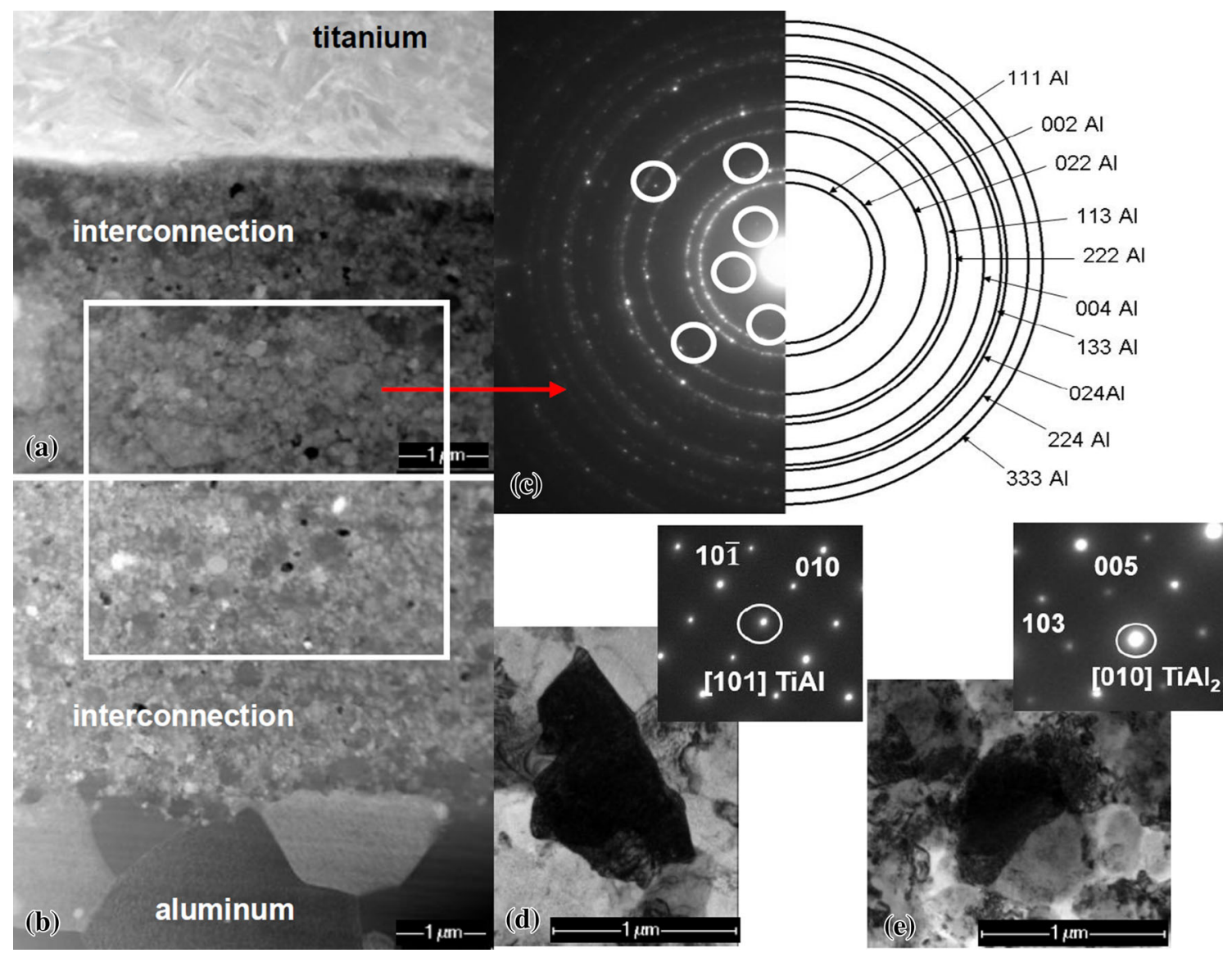

Fig. 3 The TEM micrographs showing fine crystalline microstructure of the interconnection region with adjacent $\mathrm{Al}$ and Ti clads (a, b). The SADP (c) taken from the interconnection area visible in $(a, b)$. The TEM/BF images together with the corresponding SADPs of a single grain of $\mathrm{TiAl}(\mathrm{d})$ and $\mathrm{TiAl}_{2}$ (e) phases present in the interconnection

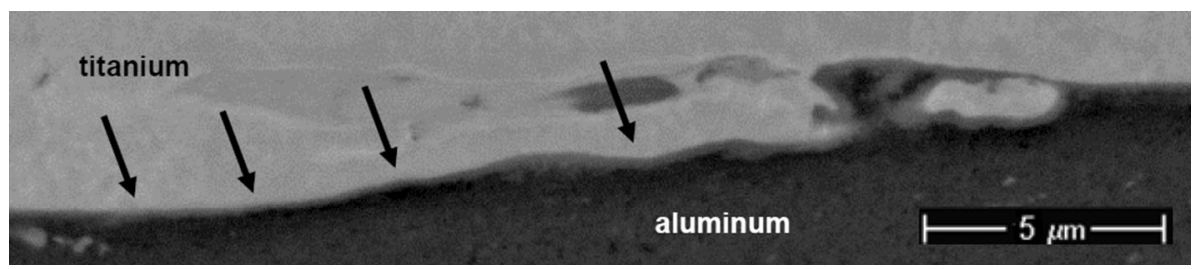

Fig. 4 The SEM/BSE image of the continuous layer obtained after annealing at $903 \mathrm{~K}$ for $5 \mathrm{~min}$

clad was manufactured. Formation of this layer $(0.3 \pm 0.1 \mu \mathrm{m})$ was revealed after the first $5 \mathrm{~min}$ of annealing (Fig. 4). The further annealing caused the growth of a uniform layer and after $100 \mathrm{~h}$ the width of $95.7 \pm 9.9 \mu \mathrm{m}$ was reached (Fig. 5). The SEM micrographs of the samples annealed for $0.25,0.5,1,2,5$, $11,15,20,25,50$, and $75 \mathrm{~h}$ are not included in this manuscript, as the changes in the microstructure are only related to the increase in the intermetallic layer width. For comparison, the annealing for $100 \mathrm{~h}$ at lower temperatures 825 and $773 \mathrm{~K}$ provides much thinner layers: $9.7 \pm 1.3 \mu \mathrm{m}$ and $0.7 \pm 0.1 \mu \mathrm{m}$, respectively (Fig. 5).

In the work of Bataev et al. (Ref 7) and Foadian et al. (Ref 17) after annealing for $100 \mathrm{~h}$ at $903 \mathrm{~K}$, the layer had a width of $250 \mu \mathrm{m}$ and about $210 \mu \mathrm{m}$, respectively. Differences in obtained results come from the fact that during annealing different atmosphere was used-air (Ref 7) and ambient
(Ref 17). Furthermore, the layer width in the following research was measured only in the rather flat parts of the samples between nodes.

\subsection{The Growth Kinetics of $\mathrm{TiAl}_{3}$ Intermetallic Phase at $903 \mathrm{~K}$}

Three temperatures in annealing experiment were used to follow the microstructure changes at the $\mathrm{Al} / \mathrm{Ti}$ interface versus temperature, especially the intermetallic growth kinetics (Fig. 5a) and the initial evolution of the interface microstructure.

As it was mentioned in the previous paragraph, the $\mathrm{TiAl}_{3}$ phase was the only one obtained in the flat regions, while all $\mathrm{Ti}_{3} \mathrm{Al}$, TiAl, $\mathrm{TiAl}_{2}$, and $\mathrm{TiAl}_{3}$ intermetallic phases were mixed in the nodes' regions. Therefore, the layer width was measured 

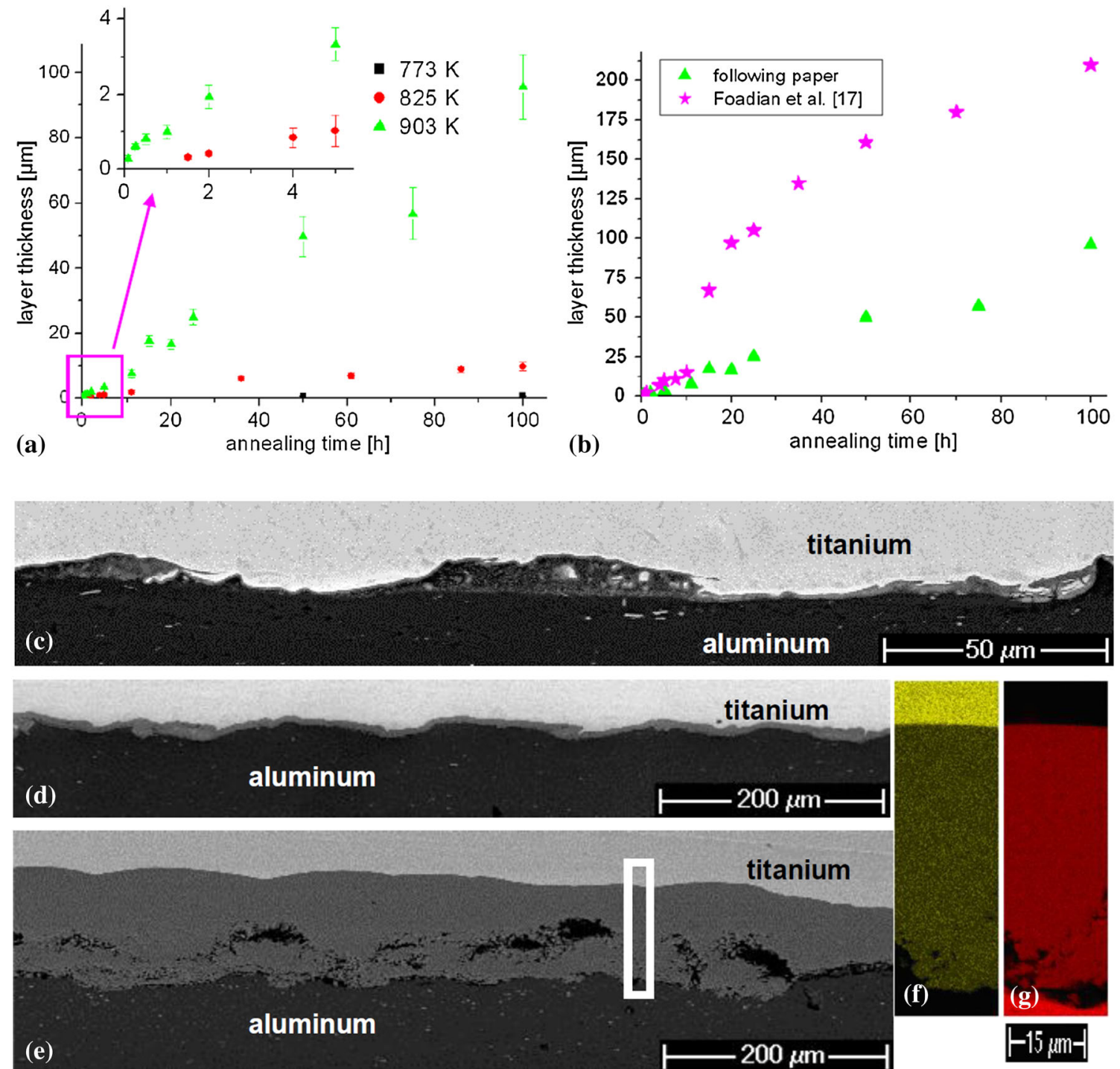

Fig. 5 Changes in the average width of the $\mathrm{TiAl}_{3}$ layer after annealing at 773,825 and $903 \mathrm{~K}$ (a) and the comparison between that obtained in the present study and by Foadian et al. (Ref 17) at $903 \mathrm{~K}$ (b). The SEM/BSE micrographs of the layer after $100 \mathrm{~h}$ of annealing at $773 \mathrm{~K}$ (c), $825 \mathrm{~K}(\mathrm{~d})$ and $903 \mathrm{~K}(\mathrm{e})$ with maps showing the distribution of $\mathrm{Ti}(\mathrm{f})$ and $\mathrm{Al}$ (g) elements inside the marked region in (e)

in more flat regions between the nodes. As the $\mathrm{TiAl}_{3}$ phase was the only one, which was present at all annealing times, the growth kinetics was determined only for this phase.

The following formula $x=k t^{n}$ describes the relationship between the layer width and the annealing time, where $x$ is an average width, $k$ is a growth rate constant, $t$ is time of annealing, and $n$ is exponential factor. One may distinguish four possible $n$ values: $1,1 \div 0.5,0.5$, or $<0.5$. The first one is related to the process governed by the chemical reaction, the second to mixed mechanism of the chemical reaction and the volume diffusion, the next one to the volume diffusion being the only mechanism, and the last one to the grain boundary diffusion.

The layer growth at $773 \mathrm{~K}$ was found to be very slow, which is economically unfavorable, and therefore, its kinetics was not established here. The use of $825 \mathrm{~K}$ is economically advantageous and even though the intermetallic layer is thinner than that obtained at $903 \mathrm{~K}$, it is of better quality. Detailed calculation of the growth kinetics at $825 \mathrm{~K}$ was presented in our previous study (Ref 22) (see also Fig. 5a). Four stages were found: incubation period $(1.5 \mathrm{~h})$, growth govern by the chemical reaction $(1.5-5 \mathrm{~h})$, when $n=0.9$ and $k=0.21 \mu \mathrm{m} /$ $\mathrm{h}^{n}$, mixed mechanism of both chemical reaction and volume diffusion and finally volume diffusion growth (36-100 h), when $n=0.48$ and $k=1.05 \mu \mathrm{m} / \mathrm{h}^{n}$.

Figure $5 \mathrm{~b}$ shows the growth kinetics plot for $903 \mathrm{~K}$ for which the exponential factor $n$ was found to be 1.16 . The incubation period was extremely short (if it indeed existed) in comparison to that determined at $825 \mathrm{~K}$, and therefore, it was not established. It can be deduced that at $903 \mathrm{~K}$, the process was solely governed by chemical reaction. The growth rate constant $k$ was determined to be $0.67 \mu \mathrm{m} / \mathrm{h}^{n}$.

Annealing at $903 \mathrm{~K}$ of explosively welded $\mathrm{Al} / \mathrm{Ti}$ samples was already studied in $\operatorname{Ref}(7,16,17)$. These experiments were carried out under various conditions in particular different atmosphere [ambient (Ref 16, 17), vacuum (this work)].

In both experiments performed in $\operatorname{Ref}(16,17)$, two steps of the growth of $\mathrm{TiAl}_{3}$ were determined. During the first $10 \mathrm{~h}$ 
(Ref 16) and $13 \mathrm{~h}$ (Ref 17) of annealing, the intermetallic phase grew linearly with $n=0.96$ and $k=1.86 \mu \mathrm{m} / \mathrm{s}^{n}$ (Ref 16) and $n=0.94$ and $k=1.98 \mu \mathrm{m} / \mathrm{s}^{n}$ (Ref 17). The value of $n$ confirmed that reaction-controlled mechanism took place. In period between 10 and $70 \mathrm{~h}(\operatorname{Ref} 16)$ and 13 and $260 \mathrm{~h}(\operatorname{Ref} 17)$ of annealing, the $n$ factor and $k$ were of 0.31 and $50.96 \mu \mathrm{m} / \mathrm{s}^{n}$ (Ref 16) and 0.31 and $52.24 \mu \mathrm{m} / \mathrm{s}^{n}$ (Ref 17), respectively. Such $n$ values indicate that the diffusion-controlled behavior takes place, with significant contribution of grain boundary diffusion $(n<0.5)$. It should be noted that in $\operatorname{Ref}(16,17)$ a certain amount of the $\mathrm{TiAl}_{3}$ phase forming clusters of the average thickness of $9.45 \pm 2.28 \mu \mathrm{m}$ was present in the state directly after explosive welding. The difference in the mechanism of $\mathrm{TiAl}_{3}$ growth in the present study and in $\operatorname{Ref}(16,17)$ may result from differences in the grain size and morphology of the initial materials as well as from their chemical composition. Also different welding conditions were used here [e.g., detonation velocity equal to about $4500 \mathrm{~m} / \mathrm{s}$ or application of ammonium nitrate mixed with TNT and gas oil as the explosive material (Ref 16, 17)].

In diffusion couple experiment presented in Ref (13), the samples were annealed at vacuum atmosphere for $12 \mathrm{~h}$ at $903 \mathrm{~K}$. The obtained value of the exponent factor $(n=1.08)$ confirmed that the process was also governed exclusively by the chemical reaction. After $12 \mathrm{~h}$, the intermetallic layer reached the width of $66.85 \pm 1.59 \mu \mathrm{m}$ (Ref 13), which is much larger than that obtained in our results (Fig. 5a, b). However, in Ref (13), samples before the annealing experiment were hot-pressed at $873 \mathrm{~K}$ for $3 \mathrm{~h}$ under $50 \mathrm{MPa}$, which resulted in the appearance of the continuous $\mathrm{TiAl}_{3}$ phase layer. Subsequent calculations of the growth kinetics and measurements of the width of the layer did not take into account this initial time of annealing.

\section{Conclusions}

The results obtained on the explosively welded Al/Ti clads led to several conclusions. In the state directly after explosion, stable $\mathrm{TiAl}_{3}, \mathrm{TiAl}$, and $\mathrm{Ti}_{3} \mathrm{Al}$ and metastable $\mathrm{TiAl}_{2}$ phases are present inside the nodes' areas. Using TEM/SADP technique, single grains of TiAl and $\mathrm{TiAl}_{2}$ were detected. The observations of initial microstructure of the interconnection area using SEM/ EBSD and TEM/BF revealed highly refined grains of aluminum mixed with randomly distributed intermetallic ones. EBSD measurements demonstrated a typical cold-rolled texture and microstructure in aluminum, while in titanium, twinned structure was observed. Furthermore, in the titanium, more twins were detected approaching the interface. The growth kinetics of $\mathrm{TiAl}_{3}$ at $903 \mathrm{~K}$ showed that only one mechanism of the growth occurs - the chemical reaction. As a consequence, the annealing at vacuum atmosphere process allows for manufacturing a layer consisting only of $\mathrm{TiAl}_{3}$ along the whole interface.

\section{Acknowledgments}

The authors thank the High Energy Technologies Works 'Explomet' (Opole, Poland) for the provision of the good quality Al/Ti clads. Samples were examined in the Accredited Testing Laboratories at the Institute of Metallurgy and Materials Science of the Polish Academy of Sciences in Cracow.

\section{Open Access}

This article is distributed under the terms of the Creative Commons Attribution 4.0 International License (http://creativecommons.org/ licenses/by/4.0/), which permits unrestricted use, distribution, and reproduction in any medium, provided you give appropriate credit to the original author(s) and the source, provide a link to the Creative Commons license, and indicate if changes were made.

\section{References}

1. G. Cam, Friction Stir Welded Structural Materials: Beyond Al-Alloys, Int. Mater. Rev., 2011, 56(1), p 1-48

2. G. Cam and S. Mistikoglu, Recent Developments in Friction Stir Welding of Al-Alloys, J. Mater. Eng. Perform., 2014, 23(6), p 19361953

3. W. Sun, X. Li, H. Yan, and K. Hokamoto, Effect of Initial Hardness on Interfacial Features in Underwater Explosive Welding of Tool Steel SKS3, J. Mater. Eng. Perform., 2014, 23, p 421-428

4. M. Urbanek, B. Masek, P. Hrone, and P. Nesvadba, The Use of Explosive Energy for Joining Advanced High Strength Low Alloy Steels, J. Mater. Eng. Perform., 2013, 22, p 748-752

5. H. Zhao, P. Li, Y. Zhou, Z. Huang, and H. Wang, Study on the Technology of Explosive Welding Incoloy800-SS304, J. Mater. Eng. Perform., 2011, 20(6), p 911-917

6. M. Acarer, B. Gulenc, and F. Findik, Investigation of Explosive Welding Parameters and Their Effects on Microhardness and Shear Strength, Mater. Des., 2003, 24, p 659-664

7. I.A. Bataev, A.A. Bataev, V.I. Mali, and D.V. Pavliukova, Structural and Mechanical Properties of Metallic-Intermetallic Laminate Composites Produced by Explosive Welding and Annealing, Mater. Des., 2012, 35, p 225-234

8. J.H. Han, J.P. Ahn, and MCh Shin, Effect of Interlayer Thickness on Shear Deformation Behavior of AA5083 Aluminum Alloy/SS41 Steel Plates Manufactured by Explosive Welding, J. Mater. Sci., 2003, 38, p 13-18

9. M. Acarer, Electrical, Corrosion, and Mechanical Properties of Aluminum-Copper Joints Produced by Explosive Welding, J. Mater. Eng. Perform., 2012, 21, p 2375-2379

10. H. Paul, L. Litynska-Dobrzynska, and M. Prazmowski, Microstructure and Phase Constitution Near the Interface of Explosively Welded Aluminum/Copper Plates, Metall. Mater. Trans. A, 2013, 44(8), p 3836-3851

11. H. Okamoto, Binary Alloy Phase Diagrams Updating Service, ASM International, Ohio, 1992

12. Y. Wei, W. Aiping, Z. Guisheng, and R. Jialie, Formation Process of the Bonding Joint in Ti/Al Diffusion Bonding, Mater. Sci. Eng. A, 2008, 480, p 456-463

13. L. Xu, Y.Y. Cui, Y.L. Hao, and R. Yang, Growth of Intermetallic Layer in Multi-laminated Ti/Al Diffusion Couples, Mater. Sci. Eng. A, 2006, 435, p 638-647

14. G. Sauthoff, Intermetallics, Weinheim, VCH Publishers, Federal Republic of Germany, 1995

15. J. Song, A. Kostka, M. Veehmayer, and D. Raabe, Hierarchical Microstructure of Explosive Joints: Example of Titanium to Steel Cladding, Mater. Sci. Eng. A, 2011, 528, p 2641-2647

16. F. Foadian, M. Soltanieh, M. Adeli, and M. Etminanbakhsh, The Formation of $\mathrm{TiAl}_{3}$ During Heat Treatment in Explosively Welded TiAl Multilayers, Iran. J. Mater. Sci. Eng, 2014, 11(4), p 12-19

17. F. Foadian, M. Soltanieh, M. Adeli, and M. Etminanbakhsh, A Study on the Formation of Intermetallics During the Heat Treatment of Explosively Welded Al-Ti Multilayers, Metall. Mater. Trans. A, 2014, 45A, p 1823-1832

18. D.V. Pavliukova, V.I. Mali, A.A. Bataev, P.S. Yartsev, T.S. Sameyshcheva, and L.I. Shevtsova, IEEE 2013 8th International Forum on Influence of the Explosively Welded Composites Structure on the Diffusion Processes Occurring During Annealing, Strategic Technology (IFOST), 28.06.2013-01.07.2013, Ulaanbaatar, 2013, p 183-186

19. J. Romberg, J. Freudenberger, J. Scharnweber, U. Gaitzsch, T. Marr, A. Eschke, U. Kühn, C.G. Oertel, I. Okulov, R. Petters, W. Skrotzki, J. Eckert, and L. Schultz, Metallographic Preparation of AluminiumTitanium Composites, Prakt. Metallogr., 2013, 50, p 739-753 
20. S.A.A. Mousavi and P.F. Sartangi, Experimental Investigation of Explosive Welding of cp-Titanium/AISI, 304 Stainless Steel, Mater. Des., 2009, 30, p 459-468

21. K.S. Vecchio, Synthetic Multifunctional Metallic-Intermetallic Laminate Composites, JOM, 2005, 57(3), p 25-31

22. D.M. Fronczek, J. Wojewoda-Budka, R. Chulist, A. Sypien, A. Korneva, Z. Szulc, N. Schell, and P. Zieba, Structural Properties of Ti/Al Clads Manufactured by Explosive Welding and Annealing, Mater. Des., 2016, 91, p 80-89

23. H. Xia, S. Wang, and H. Ben, Microstructure and Mechanical Properties of Ti/Al Explosive Cladding, Mater. Des., 2014, 56, p 1014-1019
24. L.J. Zhang, Q. Pei, J.X. Zhang, Z.Y. Bi, and P.C. Li, Study on the Microstructure and Mechanical Properties of Explosive Welded 2205/X65 Bimetallic Sheet, Mater. Des., 2003, 64, p 462-476

25. H. Paul, J. Morgiel, T. Baudin, F. Brisset, M. Prazmowski, and M. Miszczyk, Characterization of Explosive Weld Joints by TEM and SEM/EBSD, Arch. Metall. Mater., 2014, 59(3), p 1129-1136

26. B. Crossland, Explosive Welding of Metals and Its Application, Clarendon Press, Oxford, 1982, p 233 